\title{
Measurement of the Lubricant Properties Using Hall Effect Sensor: A Study on Contamination and Viscosity
}

\author{
Witsarut Sriratana, Riichi Murayama \\ Department of Intelligent Mechanical Engineering, Faculty of Engineering, Fukuoka Institute of Technology, Fukuoka, Japan \\ Email:kswitsar@kmitl.ac.th,murayama@fit.ac.jp
}

Received January 25, 2013; revised February 26, 2013; accepted March 3, 2013

Copyright (C) 2013 Witsarut Sriratana, Riichi Murayama. This is an open access article distributed under the Creative Commons Attribution License, which permits unrestricted use, distribution, and reproduction in any medium, provided the original work is properly cited.

\begin{abstract}
This study proposes the development of contamination measurement for industrial machines based on magnetic field method. A permanent magnet was used to generate the $0.17 \mathrm{~T}$ magnetic fields and Hall Effect sensor was applied to measure the contamination level of metal particles in industrial machine lubricant during operation time and to predict the replacement period if the lubricant condition does not meet the standard (NAS 1638). Contamination level of metal particles was directly related to the output voltage of Hall Effect sensor. When there was any movement of metal particles to the permanent magnet, the measured result was then transferred to a computer for analysis. This methodology could be applied to experiment the conditions of used lubricant for assessing the contamination and the metal particle remaining in the tank or inside the pipe of the machine as well as the conditions of car lubricant and other lubricants used in industrial processes.
\end{abstract}

Keywords: Contamination; Hall Effect; Lubricant; Magnetic; Particles; Viscosity

\section{Introduction}

The conditions of lubricant are vital for industrial machine efficiency as they are related to machine damage caused by lubricant deterioration. From previous studies $[1,2]$, it can be noted that machine failures would be influenced by the lubricant with low quality. Theoretically, the lubricant for each type of machine should be used in specific period. However, the lubricant conditions would be gradually deteriorated earlier than expected due to metal particles cased by machine wear itself or exterior contamination and also the maintenance period would not be appropriate for a given machine. From $[3,4]$, it was observed that more than $50 \%$ of lubricant replacement would be performed even though the lubricant is still in good condition and usable that leads to excessive cost. At present, there are several studies proposing the experiments on lubricant conditions by using several methods such as Ultrasonic measurement of viscosity of liquids, Photoacoustic measurement of liquid viscosity, Measurement of magnetic viscosity in $\mathrm{NdFeB}$, A viscosity and density meter with a magnetically suspended rotor, Capacitive sensor, IR-absorption and optical fiber sensing [5-11]. This study is an alternative measurement by using magnetic field together with Hall Effect sensor which can be applied for examining the lubricant contamination of metal particles based on NAS 1638 standard with high accuracy and reliability.

\section{Fundamental Method}

\subsection{Relationship between Metal Particles and Viscosity}

Viscosity is one of the vital parameters that play an important role on characteristic of industrial lubricant. Normally, the viscosity has influenced directly related to the flow rate of lubricant. If the viscosity of lubricant is lower than the specified value under normal operation, the efficiency of the machine can also decrease that leads to machine failures. The relationship of metal particles was the factors depending on the viscosity can be determined from the Newton's Law of viscosity in case of Dynamic and Kinematic viscosity by Equation (1).

$$
\eta=t_{\text {moving }} \frac{F}{A} \rho
$$

where $\eta$ is the viscosity $(\mathrm{Pa} \cdot \mathrm{s})$; $\rho$ is the density of the fluid $\left(\mathrm{kg} / \mathrm{m}^{3}\right)$;

$F$ is the force $(\mathrm{N})$;

$A$ is the area of oil containers $\left(\mathrm{cm}^{3}\right)$; 
$t_{\text {moving }}$ is moving time to permanent magnet of metal particles $(\mathrm{s})$.

\subsection{Hall Effect Sensor}

Hall Effect sensor is a small passive transducer which is applicable in several purposes. The output voltage is generated when the constant current transmitting through a semiconductor namely Hall generator is diverted [12]. In this study, the magnetic flux density $(B)$ generated by sensor module can be analyzed by Lorentz force of the magnetic field on an electron $(q)$ when changing the relative angle $(\theta)$ as given in Equation (2). $v$ is the velocity of electron due to electric field. Hall voltage is generated by magnetic field as shown in Equation (3).

$$
\begin{aligned}
& F=q v B \sin \theta \\
& V_{H}=\frac{R_{H}}{d} I B
\end{aligned}
$$

where $V_{H}$ is output voltage from Hall Effect sensor $(\mathrm{V})$; $d$ is the thickness of the Hall generator $(\mathrm{mm})$;

$R_{H}$ is Hall coefficient $(\Omega)$;

$I$ is the constant current $(\mathrm{mA})$.

\section{System Components}

\subsection{Sensor Module}

The contamination sensor module consisted of a Hall Effect sensor mounted on a permanent magnet $(0.17 \mathrm{~T})$ size is $12 \mathrm{~mm}$ of width $15 \mathrm{~mm}$ of length and $2 \mathrm{~mm}$ of thickness. The gap between Hall Effect sensor and permanent magnet is $3 \mathrm{~mm}$. in order to protect the saturated output voltage of Hall Effect sensor in case of the magnetic field over the range. The output voltage from the Hall Effect sensor was therefore constant and used for comparing to the sensing output voltage, which was generated when metal particles move to a permanent magnet [8], as shown in Figure 1.

The permanent magnet generates a magnetic field, which can be effect to metal contaminants in the lubricant that is cause of the magnetic field changed according to the weight of the contaminants. The Hall Effect sensor can detect changing of magnetic field and gener-

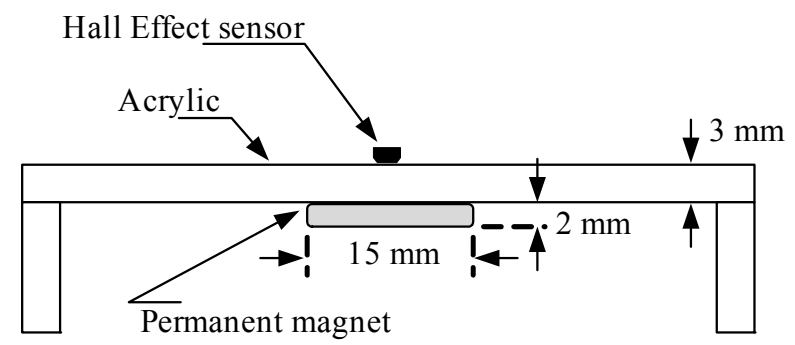

Figure 1. Installation of a Hall Effect sensor and a permanent magnet (top view). ate the voltage output to the 12 bit-analog to digital convertor for sending data to the data acquisition based on microcontroller then it passes data to store on the computer and data analysis.

\subsection{Reference Metal Particles}

Contamination can be influenced by several causes such as machine wear and corrosion or exterior contamination from exposed surrounding. As a result, wear particles could be non-ferrous and ferrous metal that lead to the lower efficiency of the machine and also machinery damages. Normally, the size of particles would range from $1 \mu \mathrm{m}$ to $40 \mu \mathrm{m}$. The particles with 20 $\mu \mathrm{m}$ to $30 \mu \mathrm{m}$ of size can directly cause the machine wear while those with less than $1 \mu \mathrm{m}$ of size would insignificantly affect [12]. Therefore, this study presents the measurement of ferrous metal contamination in machine lubricant, which essentially influences the variation of magnetic field depending on the metal contamination level.

Figure 2 shows the reference metal particles used for the experiments was analyzed by SEM (Scanning Electron Microscope) with a scan speed $=2$, Extra high tension $(\mathrm{EHT})=10 \mathrm{kV}$, Work distance $(\mathrm{WD})=12 \mathrm{~mm}$, and Magnification $(\mathrm{Mag})=2 \mathrm{kX}$. The size of metal particle varied from $1 \mu \mathrm{m}$ to $100 \mu \mathrm{m}$.

There were 3 lubricants tested in this study. About $25 \mathrm{ml}$ of each sample was filled in 10 sets of $50 \mathrm{ml}$ oil containers size is $0.3 \mathrm{~mm}$ of thickness, $20 \mathrm{~mm}$ of width, $40 \mathrm{~mm}$ of length and $70 \mathrm{~mm}$ of height. The reference metal particles was added in $0.1 \mathrm{~g}, 0.2 \mathrm{~g}, 0.3 \mathrm{~g}, 0.4 \mathrm{~g}$, $0.5 \mathrm{~g}, 0.6 \mathrm{~g}, 0.7 \mathrm{~g}, 0.8 \mathrm{~g}, 0.9 \mathrm{~g}$ and $1 \mathrm{~g}$ increment, respectively as shown in Figures $\mathbf{3}$ and $\mathbf{4}$.

The sensor module and each oil container filled with test the lubricant were placed in the designed positions during the experiments for accurate and precise results. As a result, the velocity of the reference metal particles can be varied by the lubricant viscosity as the velocity

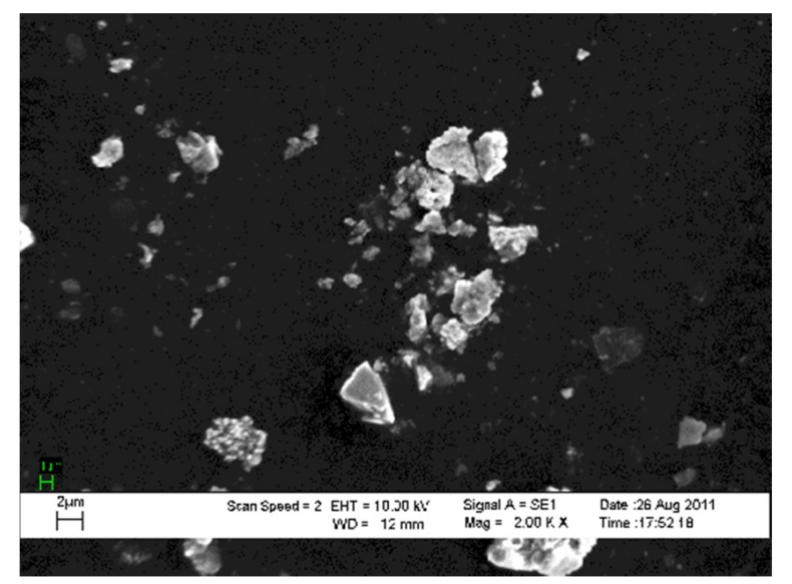

Figure 2. Reference metal particles size by SEM at $2 \mathrm{kX}$. 


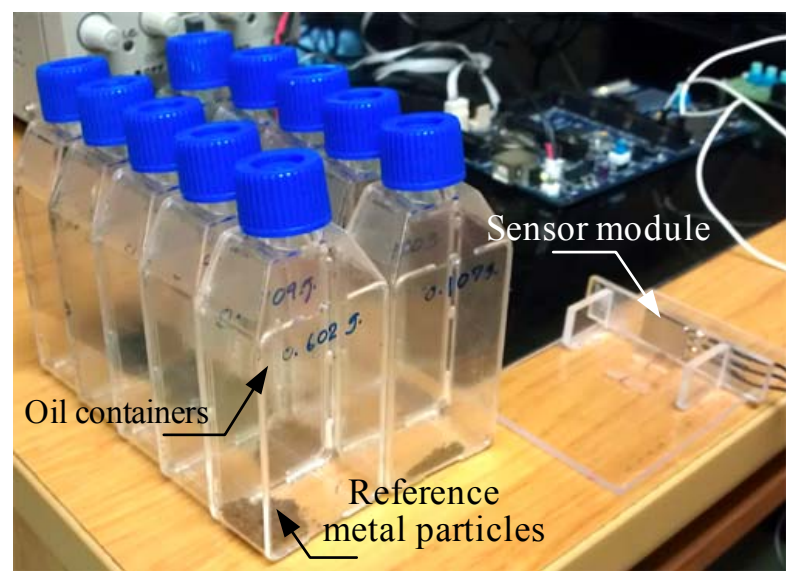

Figure 3. Oil containers for lubricant testing.

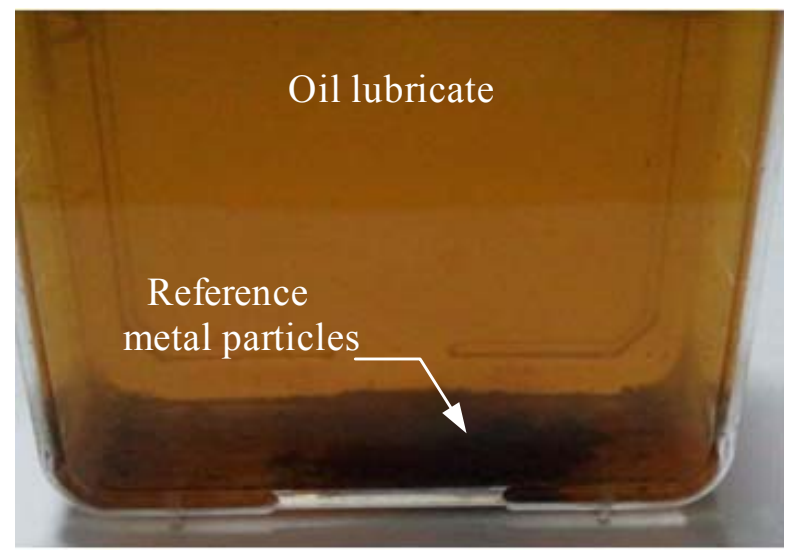

Figure 4. Lubricant and reference metal particles.

would be low for a high viscosity lubricant and on the other hand, the velocity would be high for a low viscosity lubricant. Therefore, the velocity of the metal particles is a function of the lubricant viscosity.

\section{Experimental Condition}

Lubricants namely SAE 15W-40, SAE 20W-50 and ISO VG 100 were selected for experiments in this study. The lubricant can gradually change its properties during operation time. In this study, the measurement of lubricant was therefore divided into 2 parts: contamination of metal particles and viscosity of lubricant. In this methodology, metal particles was added to $25 \mathrm{ml}$ of lubricant oil containers by varying the weight from $0.1 \mathrm{~g}$ to $1 \mathrm{~g}$ and then stirred for about 3 seconds before testing as shown in Figure 5. The average values of output voltage from Hall Effect sensor starting from $3.736 \mathrm{~V}$ and then increasing continuously when metal particles moving close to permanent magnet.

In this experiment, repetitive measurements were also done 10 measured results for one value of the metal particles weight to estimate the precision and repea- tability of the sensor module. The measured results were in the form of an electrical voltage obtained from the output of the Hall Effect sensor. These output values were dependent on the velocity of the metal particles moving to the permanent magnet as shown in the Figures 6 and 7.

\subsection{Measurement of Contamination}

The measurement of contamination based on NAS 1638 standard was performed by counting the number of particles and dividing the level of contamination into 14 degrees starting from NAS 00 to NAS 12 . The incremental number of particles in each step of degree was double. The level of contamination exceeding level 12 can be determined by using extrapolation [11] as shown in Table 1. However, in this study presents the methodology to experiment the ISO VG100 lubricant due to widespread use of this lubricant in industry such as gearbox and also refers to the metal particles contamination when the number of particles exceeds the maximum allowance of L-CKC industrial closed gear oil standard as provided in Table 2. Typically, the maximum value for lubricant to be replaced should be $0.5 \%$ or equivalent NAS 18 standard, the difference level of contamination as shown in Figure 8. Therefore, the sensor module used in this study (Hall Effect sensor) was calibrated by using the weight of contamination starting from NAS 12 onward until the weight of metal particles reaching $1 \mathrm{~g}$ [13].

\subsection{Measurement of Viscosity}

The relationships of the moving metal particles, lubricant viscosity and output voltage of the Hall Effect sensor

Table 1. Weight contamination standard NAS 1638.

\begin{tabular}{cccccc}
\hline Contamination degree & 12 & 13 & 14 & 15 & 16 \\
\hline $\mathrm{mg} / 25 \mathrm{ml}$ & 1.25 & 2.5 & 5 & 10 & 20 \\
Contamination degree & 17 & 18 & 19 & 20 & 21 \\
$\mathrm{mg} / 25 \mathrm{ml}$ & 40 & 80 & 160 & 320 & 640 \\
\hline
\end{tabular}

Table 2. L-CKC exchanging standard of industrial closed gear oil (method: SH/T0586).

\begin{tabular}{cc}
\hline Item & $\begin{array}{c}\text { Exchanging oil } \\
\text { Standard }\end{array}$ \\
\hline Appearance & Abnormity \\
Movement viscosity $\left(40^{\circ} \mathrm{C}\right)$ rate of change $/ \%>$ & +15 or -20 \\
Moisture $/ \%$ & 0.5 \\
Mechanical impurities $/ \% \geq$ & 0.5 \\
Copper corrosion $\left(100^{\circ} \mathrm{C}\right), 3 \mathrm{~h} /$ degree $\geq$ & $3 \mathrm{~b}$ \\
Timken $\mathrm{OK}$ value $/ \mathrm{N} \leq$ & 133.4 \\
\hline
\end{tabular}




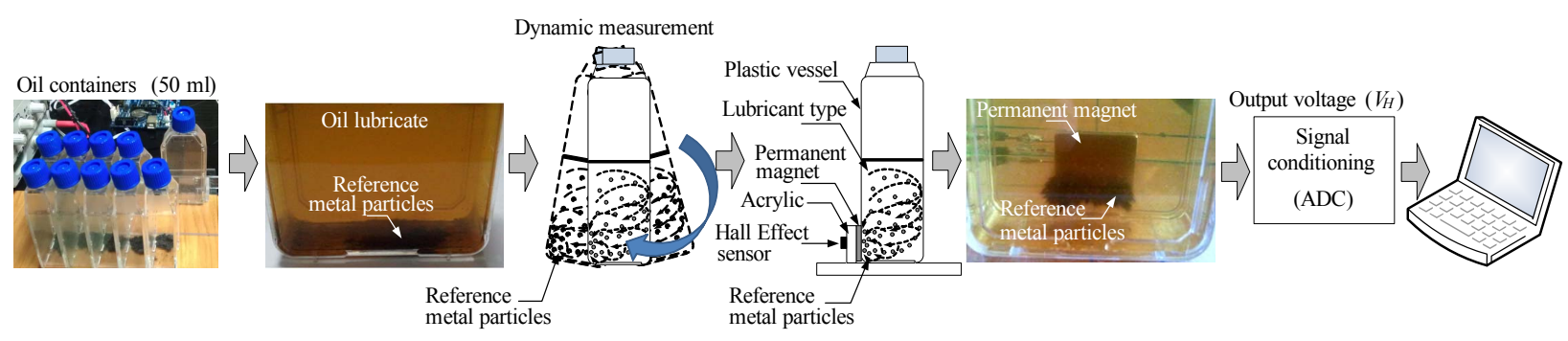

Figure 5. Illustration of all turbulent metal particles.

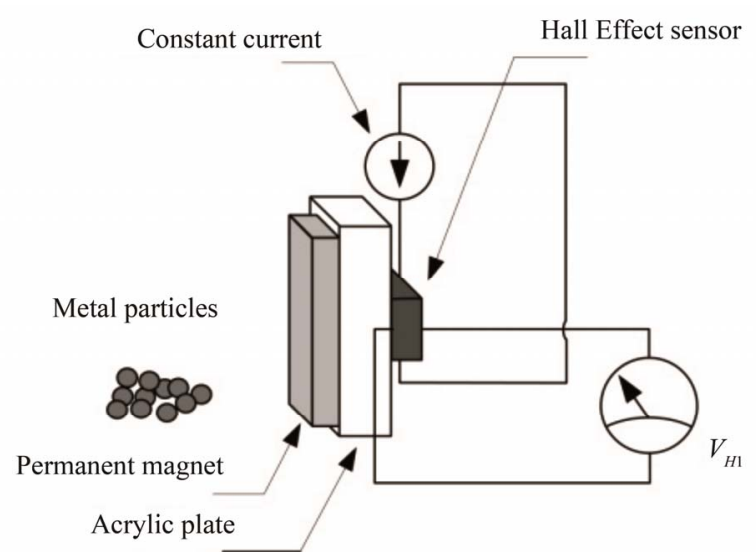

Figure 6. Output voltage from Hall Effect sensor initially at $3.736 \mathrm{~V}$ before testing.

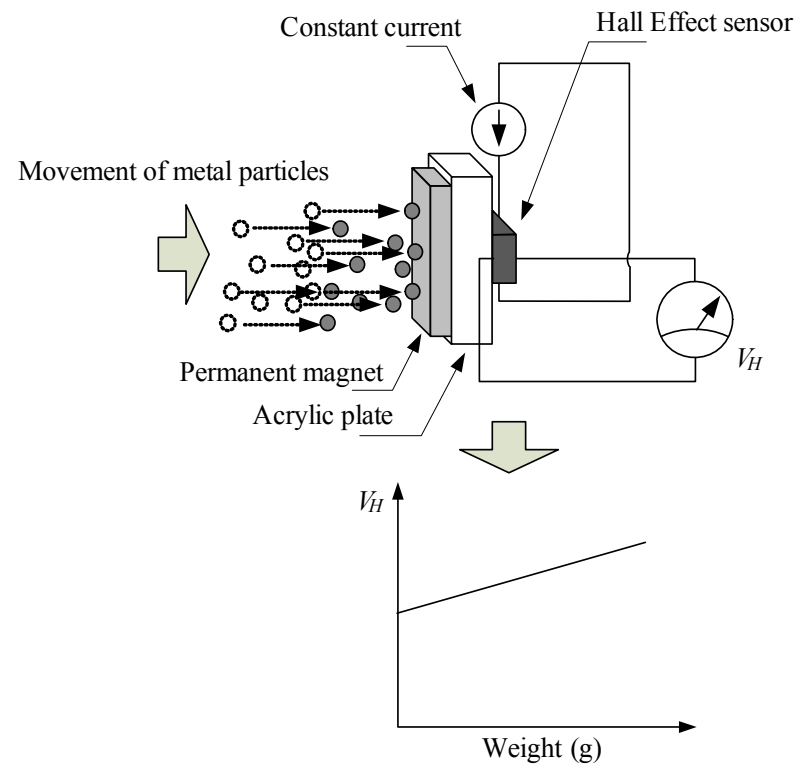

Figure 7. Increase of Output voltage from Hall Effect sensor when metal particles are moving to permanent magnet.

were determined are shown in the Figure 9. When the relationship is $T_{A}>T_{B}>T_{C}$ then $\eta_{A}>\eta_{B}>\eta_{C}$ where $T_{A}, T_{B}$, and $T_{C}$ are the variation from the starting point to a stable point of output from the sensor module, $\eta_{A}, \eta_{B}$, and $\eta_{C}$ are the viscosity of each lubricant [14].

From the empirical study, it can be determined using

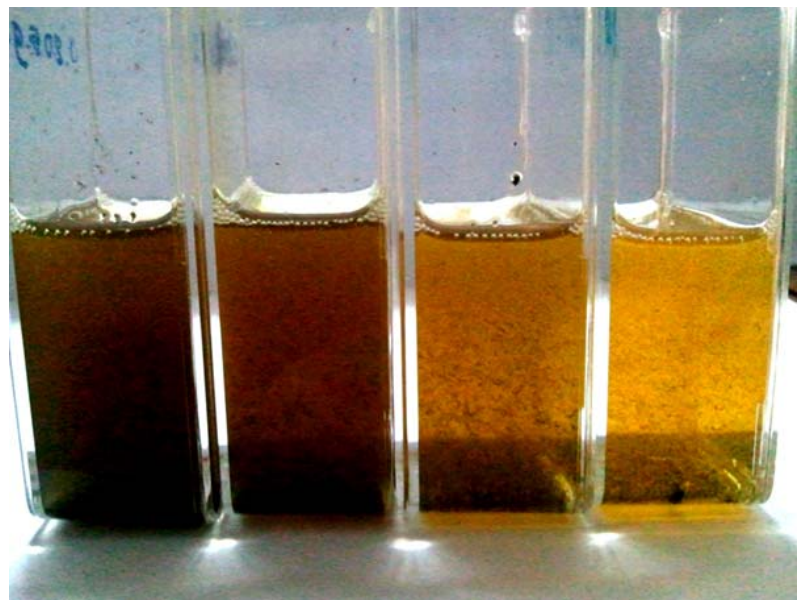

Figure 8. Difference level of contamination in ISO VG 100.

(s)

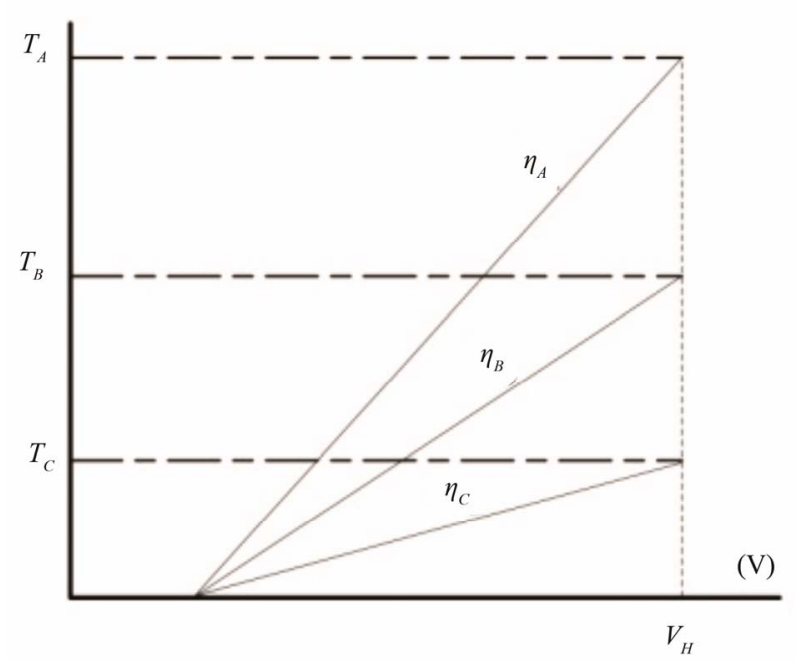

Figure 9. The relationships of viscosity and output voltage of Hall Effect sensor.

Equation (4).

$$
t_{\text {moving }}=m \times V_{H}+c
$$

where $m$ is the slope as a function of mass of metal particles and viscosity $(\mathrm{s} / \mathrm{V}) ; c$ is the constant.

Changing metal particles weight for measuring the lubricant viscosity characteristic was performed in order to determine the appropriate reference metal particles weight 
for $25 \mathrm{ml}$ of lubricant in the oil containers and further use as a reference weight.

\section{Experiment Results}

\subsection{The Results of Contamination}

From experimental study of ISO VG 100 lubricant shown in Table 3, it can be noted that the variation of output voltage from Hall Effect sensor can initially measured from $0.01 \mathrm{~g}$ of contamination onward with $\pm 1 \mathrm{mV}$ of the maximum error, as shown in Figure 10. Compared to NAS 15, the system developed can effectively measure the contamination level for replacement of lubricant based on the specific standard. However, for NAS 14 downward, insignificant variation of output voltage from Hall Effect sensor was observed or this system cannot distinguish the contamination of metal particles lower than NAS 14. The standard variation of the experimental results is presented in Figure 11, which can be noted that the greater number of metal particles would lead to the higher standard deviation. It is because the quantity of wear particles is greater than the area of permanent magnet that causes the saturated magnetic field.

Table 3. Output voltage of the Hall Effect sensor.

\begin{tabular}{cccc}
\hline Particles (g) & Output (V) & Particles (g) & Output (V) \\
\hline 0.001 & 3.737 & 0.3 & 3.788 \\
0.002 & 3.737 & 0.4 & 3.799 \\
0.005 & 3.737 & 0.5 & 3.809 \\
0.01 & 3.739 & 0.6 & 3.818 \\
0.02 & 3.741 & 0.7 & 3.825 \\
0.04 & 3.745 & 0.8 & 3.831 \\
0.08 & 3.752 & 0.9 & 3.836 \\
0.1 & 3.758 & 1 & 3.842 \\
0.2 & 3.774 & & \\
\hline
\end{tabular}

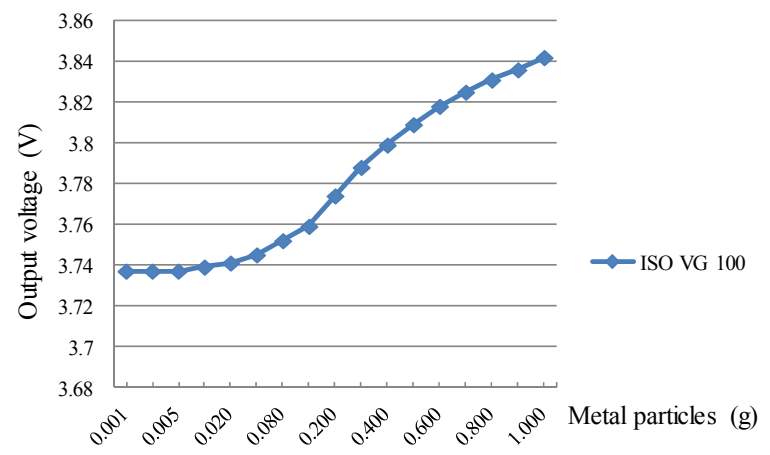

Figure 10. Output voltage of Hall Effect sensor corresponding to weigh level.

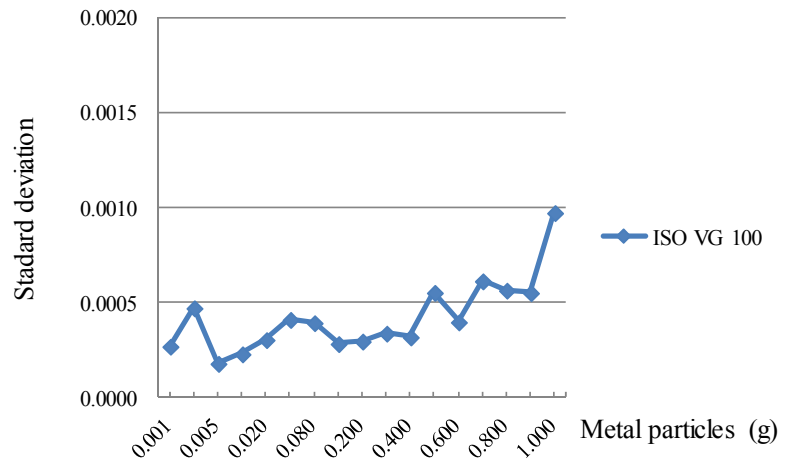

Figure 11. Standard deviation of contamination in ISO VG 100.

The same experimental methodology was applied for testing other different lubricant types which are used for engines based on the standards of SAE $15 \mathrm{~W}-40$ and SAE 20W-50 as shown in Figure 12. From experiments, it was observed that Hall Effect sensor could measure the variation of metal particles contamination without limitations of lubricant types.

\subsection{The Results of Viscosity}

From experiment, we considering the time consumed when the metal particles moved to the permanent magnet for each experimental weight, it was observed that the output voltage from the Hall Effect sensor was smoothly and consistently varied as shown in Figures 13-15. It can also be noted that the appropriate weights for the experiments ranged from $0.1 \mathrm{~g}$ to $1 \mathrm{~g}$ due to sharp slope before reaching a stable point. From the detailed analysis, the appropriate reference weights would be $0.6 \mathrm{~g}$ and 0.8 g. Therefore, these 2 weight values were further used as a reference for the other lubricant types.

In this paper present only a case of ISO VG 100 (0.6 g and $0.8 \mathrm{~g}$ of weight). The experiment was conducted to observe the relationship of output voltage and viscosity tested. It can be divided the experiment into two sections which were based on the time period of the metal particles moving to the permanent magnet and the time to reach the stable point as shown in Figures $\mathbf{1 6}$ and $\mathbf{1 7 .}$ The developed system can be expressed by the variation in the output voltage using a third degree polynomial as expressed by Equation (5) and second degree polynomial as expressed by Equation (6), respectively.

$$
\begin{gathered}
y=9 E-05 x^{3}-0.0019 x^{2}+0.0138 x+3.7755 \\
y=-0.0008 x^{2}+0.0104 x+3.7916
\end{gathered}
$$

The linear relationship of the output voltage from the Hall Effect sensor on the $\mathrm{Y}$ axis and viscosity testing on the $\mathrm{X}$ axis as a function of the magnetic field variation in 


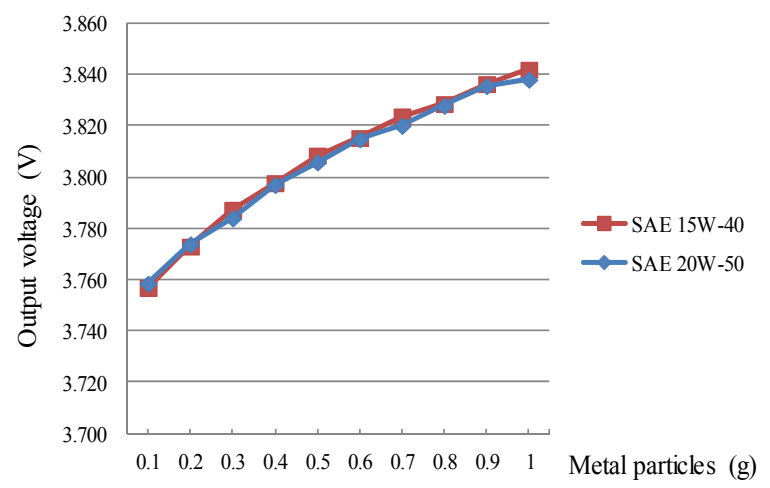

Figure 12. Effect of metal particle in contamination standard tests in the case of measuring motor oil SAE 15W-40 and SAE 20W-50.

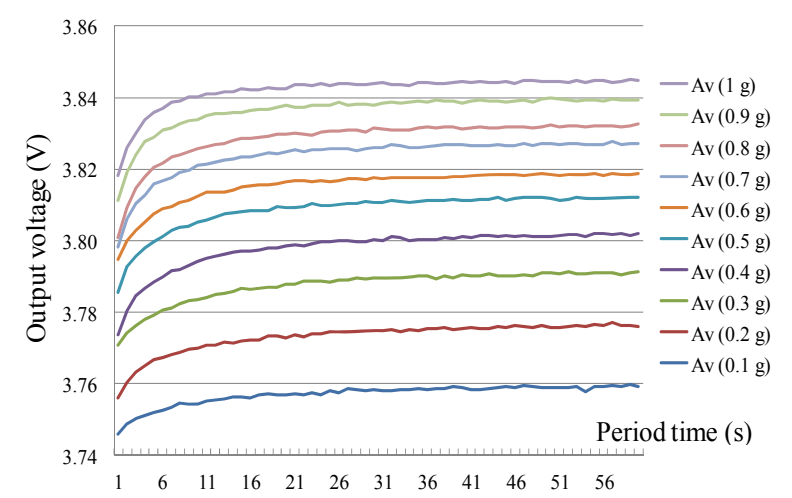

Figure 13. Output voltage variation and period time (SAE 15W-40).

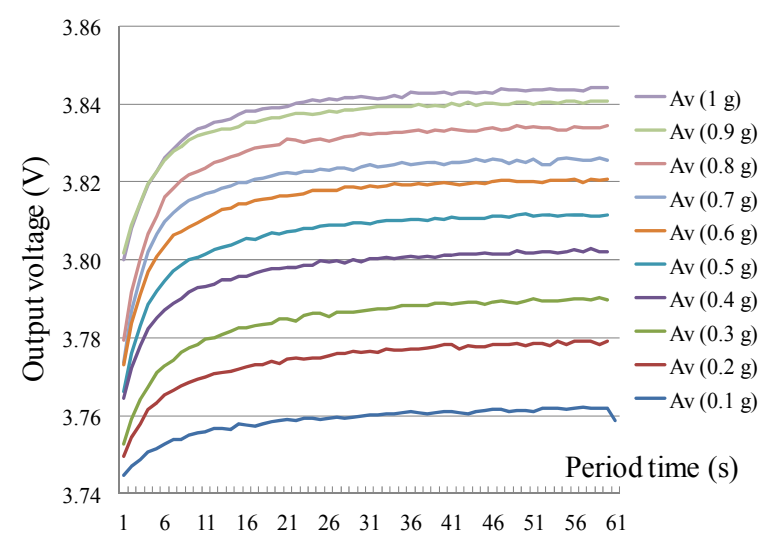

Figure 14. Output voltage variation and period time (SAE 20W-50).

case of $0.6 \mathrm{~g}$ as shown in Figure 18 and that in case of $0.8 \mathrm{~g}$ as shown in Figure 19. The relationship of an electrical voltage in a third degree polynomial and viscosity tested from starting point to stable point generated by sensor module ( $0.6 \mathrm{~g}$ of metal particles) as shown in Figure 20 and that in case of 0.8 of metal particles as shown in Figure 21.

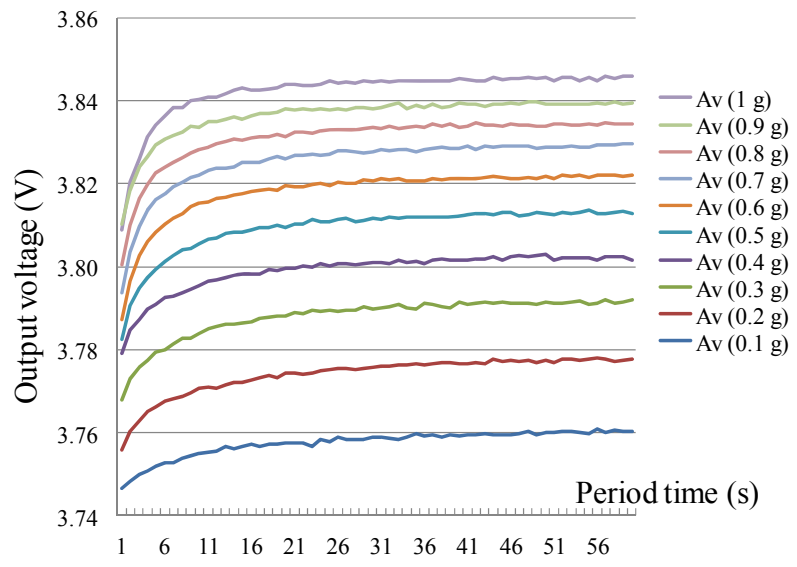

Figure 15. Output voltage variation and period time (ISO VG 100).

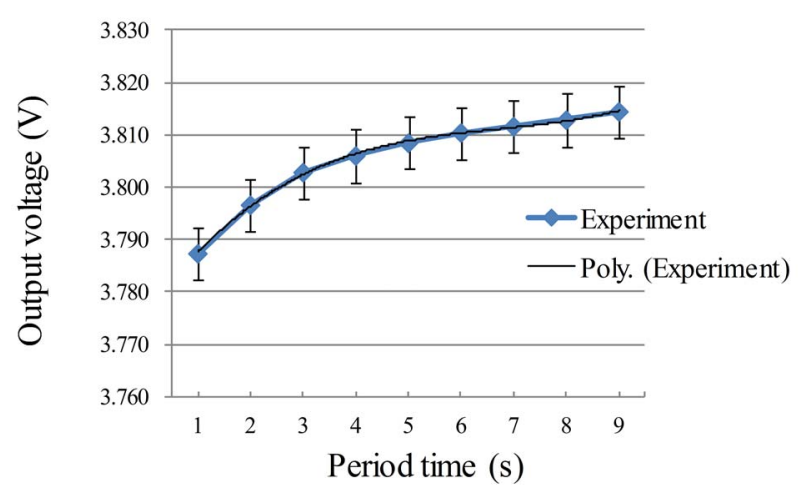

Figure 16. Relationship of output voltage and viscosity tested in a third degree polynomial (ISO VG 100 (0.6 g)).

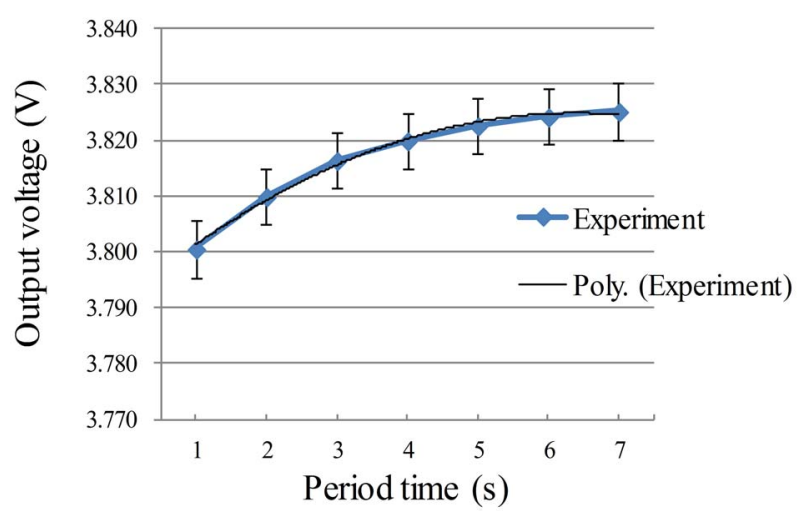

Figure 17. Relationship of output voltage and viscosity tested in a second degree polynomial (ISO VG 100 (0.8 g)).

\subsection{Viscosity Analysis}

Details of time to stable point, Mean, and Standard deviation at the stable point of those 3 selected lubricant using $0.6 \mathrm{~g}$ and $0.8 \mathrm{~g}$ of metal particles weight are presented in Tables 4 and 5 [15].

However, if the reference metal particles weight is 


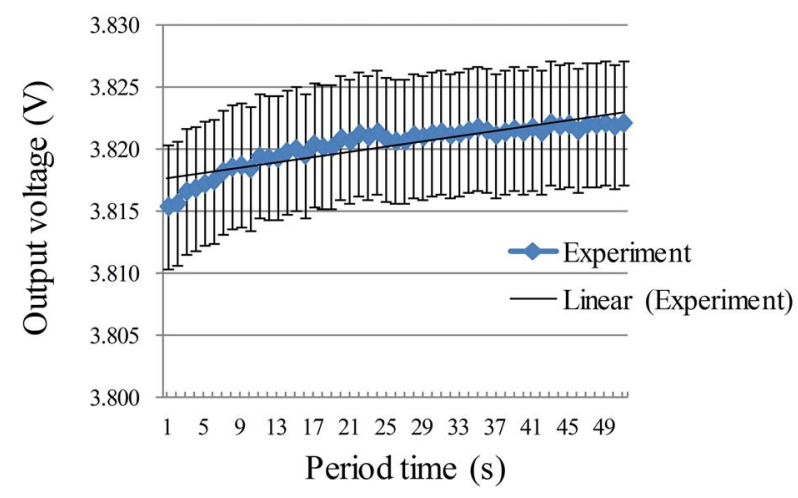

Figure 18. Linear relationship of output voltage and viscosity tested at the stable point ( $0.6 \mathrm{~g}$ of metal particles).

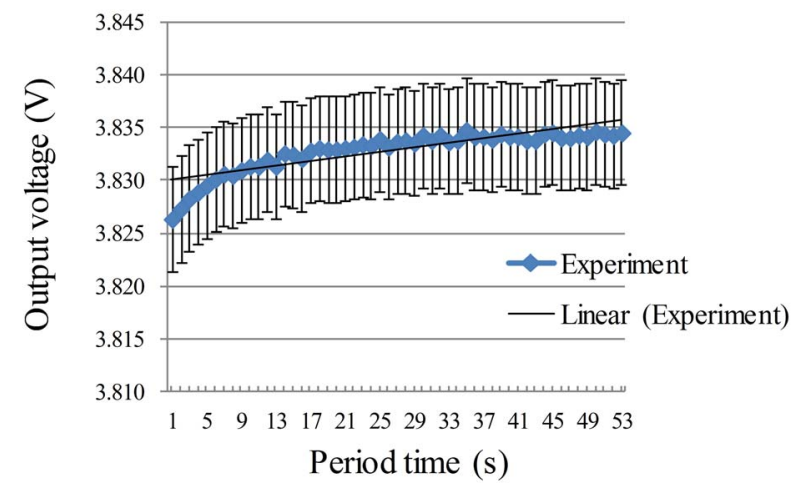

Figure 19. Linear relationship of output voltage and viscosity tested at the stable point ( $0.8 \mathrm{~g}$ of metal particles).

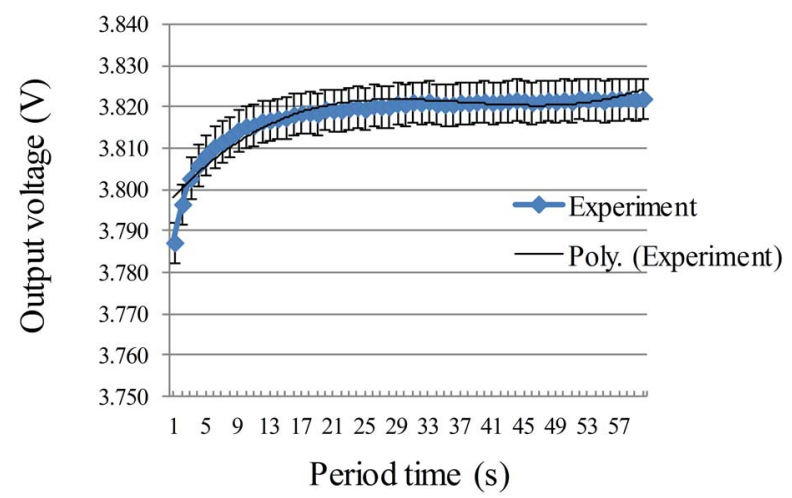

Figure 20. Relationship of electrical voltage and viscosity tested in a third degree polynomial ( $0.6 \mathrm{~g}$ of metal particles).

Table 4. Mean and standard deviation at the stable point of $0.6 \mathrm{~g}$ reference metal particles.

\begin{tabular}{cccc}
\hline Lubricates grade & $\begin{array}{c}\text { Moving } \\
\text { time }(\mathrm{s})\end{array}$ & $\begin{array}{c}\text { Mean } \\
(\mathrm{V})\end{array}$ & Standard deviation \\
\hline ISO VG 100 & 10 & 3.81 & 0.008 \\
SAE 15W-40 & 15 & 3.81 & 0.007 \\
SAE 20W-50 & 17 & 3.8 & 0.013 \\
\hline
\end{tabular}

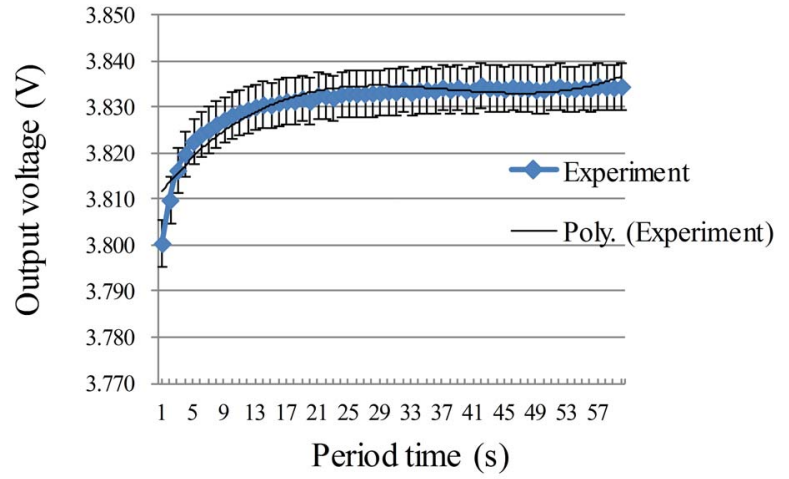

Figure 21. Relationship of electrical voltage and viscosity tested in a third degree polynomial $(0.8 \mathrm{~g}$ of metal particles).

Table 5. Mean and standard deviation at the stable point of $0.8 \mathrm{~g}$ reference metal particles.

\begin{tabular}{cccc}
\hline Lubricates grade & $\begin{array}{c}\text { Moving } \\
\text { time (s) }\end{array}$ & $\begin{array}{c}\text { Mean } \\
(\mathrm{V})\end{array}$ & Standard deviation \\
\hline ISO VG 100 & 7 & 3.817 & 0.009 \\
SAE 15W-40 & 10 & 3.818 & 0.008 \\
SAE 20W-50 & 13 & 3.813 & 0.014 \\
\hline
\end{tabular}

higher than $0.9 \mathrm{~g}$, the output voltage from Hall Effect sensor would be not constant. A significant influence on the lowest viscosity of the lubricant is as shown in Figure 22. It was found that SAE $15 \mathrm{~W}-40$ exhibited least time consumed to stable point $(5 \mathrm{~s})$ followed by ISO VG 100 (6 s) and SAE 20W-50 (12 s), respectively.

\section{Conclusions}

From experiment, it was found that the system developed could provide accurate and reliable results. The sensor module has been developed for the measurement of contamination of the lubricant that was already mentioned in this article. The principle of the magnetic field is measured using a Hall Effect sensor, which has been created. It can be used to measure the amount of contamination of the metal (ferrous) in the lubricant. The reference standard for detecting lubricant is NAS 1638. The results showed that the sensor can measure the amount of contamination of the metal, which is associated with change in the magnetic field in the lubricant. This system can measure contamination level since NAS 15 , which can define the wear and tear of machinery, sufficient to indicate drain properly. The advantages of using the principles of measuring magnetic fields are able to reduce errors due to the turbidity of the lubricant due to each brand and grade the clarity and intensity of color as well, which need to be careful when using the optical measurement. Measurement system can be improved in terms 


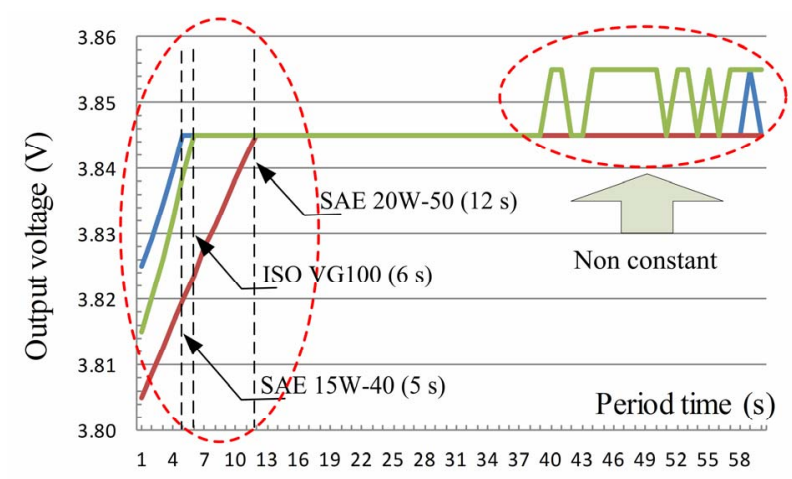

Figure 22. Time consumed to stable point for $1 \mathrm{~g}$ reference metal particles.

of sensitivity and ability of measuring the contamination at a lower level, NAS 15 by selecting the sensor that has high sensitivity to measure magnetic fields. Moreover, it can be updated to install on the machine that can measure in real time to prevent the damage of machinery.

In case of viscosity measurement, it was also observed that the output voltage from Hall Effect sensor was smoothly and consistent varied considering from period time of metal particles moving to permanent magnet and reaching the stable point. Metal particles with various weights was added in $25 \mathrm{ml}$ lubricant and then experimented in order to estimate the appropriate weight to be used for testing. The appropriate weights of metal particles for experiment would be ranged from $0.1 \mathrm{~g}$ until $1 \mathrm{~g}$. If the reference metal particles weight is greater than $1 \mathrm{~g}$, the output voltage from Hall Effect sensor would be non-constant. However, the influence on the lowest viscosity of the lubricant was insignificant and the influence on the lubricant viscosity higher than $9500 \mathrm{mPa}$.s at $-15^{\circ} \mathrm{C}$ (Cranking) and $60,000 \mathrm{mPa} . \mathrm{s}$ at $-20^{\circ} \mathrm{C}$ (Pumping) was low. Therefore, we can be estimating the ratio between weight of the reference metal particles $(0.8 \mathrm{~g})$ and volume of the lubricant as $\approx 0.1019 \mathrm{ml}$ per $25 \mathrm{ml}$.

\section{REFERENCES}

[1] M. H. Jones, "Tribology-A Key Element in Condition Monitoring," Proceedings of Condition Monitoring, Oxford, 2001, pp. 20-29.

[2] Q. Meng, "Study on the On-line Oil Monitor Based on Optical Fiber Sensor," Chinese Hydraulics \& Pneumatics, Vol. 5, 2006, pp. 34-37.

[3] B. W. Wilson and G. Silvernail, "Automated In-Line Machine Fluid Analysis for Marine Diesel and Gas Turbine Engines," International Condition Monitoring Confer- ence, Mobile, 2002, pp. 129-135.

[4] R. Guojun, T. Derong and Q. Jinyu, "An On-Line Monitoring Technique for Contamination Degree of Diesel Engine Lubricating Oil," Internal Combustion Engines, Vol. 32, 2005, pp. 36-38.

[5] F. Buiochi, R. T. Higuti, C. M. Furukawa and J. C. Adamowski, "Ultrasonic Measurement of Viscosity of Liquids," IEEE Ultrasonics Symposium, Vol. 1, San Juan, 22-25 October 2000, pp. 525-528. doi:10.1109/ULTSYM.2000.922604

[6] C. Lou and D. Xing, "Photoacoustic Measurement of Liquid Viscosity," IEEE Applied Physics Letters, Vol. 96, No. 21, 2010, Article ID: 211102. doi:10.1063/1.3435462

[7] D. C. Crew, P. G. McCormick and R. Street, "Measurement of Magnetic Viscosity in NdFeB," IEEE Transactions on Magnetics, Vol. 32, No. 5, 1996, pp. 4356-4358. doi: $10.1109 / 20.538867$

[8] M. Bano, I. Strharsky, and I. Hrmo, "A Viscosity and Density Meter with a Magnetically Suspended Rotor," IEEE Scientific Instruments, Vol. 74, No. 11, 2003, pp. 4788-4793. doi:10.1063/1.1614881

[9] D. Yang, X. Zhang, Z. Hu and Y. Yang, "Oil Contamination Monitoring Based on Dielectric Constant Measurement," Measuring Technology and Mechatronics Automation, Zhangjiajie, 2009, pp. 249-252.

[10] A. Agoston, C. Otsch, J. Zhuravleva and B. Jakoby, “An IR-Absorption Sensor System for the Determination of Engine Oil Deterioration," Proceedings of IEEE on Sensors, Vol. 1, Austria, 24-27 October 2004, pp. 463-466. doi:10.1109/ICSENS.2004.1426200

[11] Z. Pang, N. Shi, G. Meng and W. Li, "Development of In-Line Oil Contamination Sensor for Lubricant of Scraper Conveyor Reducer," 9th International Conference on Electronic Measurement \& Instruments (ICEMI09), Beijing, 16-19 August 2009, pp. 4808 - 4812.

[12] E. Ramsden, "Hall-Effect Sensor: Theory and Applications," Elsevier, Burlington, 2006.

[13] C. Chaiyachit, S. Satthamsakul, W. Sriratana and T. Suesut, "Hall Effect Sensor for Measuring Metal Particles in Lubricant," International Multi Conference of Engineers and Computer Scientists 2012 (IMECS 2012), Hong Kong, 14-16 March 2012, pp. 894-897.

[14] W. Sriratana and R. Murayama, "Lubricant Viscosity Measurement Using Hall Effect Sensor," The Society of Instrument and Control Engineers (SICE Annual Conference 2012), Akita, 20-23 August 2012, pp. 23-26.

[15] International Organization for Standardization, "Guide for Expression of Uncertainty in Measurement," International Organization for Standardization, 2nd Edition, Switzerland, 1995. 